\title{
REINVENTÁNDOSE A SÍ MISMA: DE FANNIE CORALIE PERKINS A FRANCES PERKINS
}

\author{
REINVENTING HERSELF: FROM FANNIE CORALIE PERKINS TO FRANCES \\ PERKINS
}

Catalina Torres Marquínez

UNED de Madrid

\section{Resumen:}

Fannie Coralie Perkins, o Frances Perkins, fue una figura clave para el mundo laboral en Estados Unidos. Su gran compromiso con la sociedad de la época la llevaron a convertirse en una de las principales impulsoras de la Ley de Seguridad Social. Este artículo pretende profundizar toda su trayectoria política.

\section{Palabras Claves:}

Frances Perkins, mujer, trabajo social.

\section{Abstract:}

Fannie Coralie Perkins, or Frances Perkins, was a key figure for working world in United States. Her great commitment with the society in that time brought her to become one of the main supporter of the Social Security Law. This article aims to go deeper into her political career.

\section{KEY WORD:}

Frances Perkins, woman, social work. 


\section{INTRODUCCIÓN}

Una mujer no demasiado agraciada en apariencia física, vestida con ropas que le hacían pasar desapercibida e incluso le daban un aire "maternal" o demasiado serio para su edad, sombrero tipo tricornio, siempre más ancho que sus mejillas, consejo que nunca olvidaría de su madre y que supondría una marca de identificación a lo largo de su vida.

Fannie Coralie Perkins, conseguiría llegar a ser la primera mujer miembro del Gabinete político del presidente F.D.Roosevelt durante doce años, desde marzo de 1933 hasta julio de 1945. Este puesto clave que desempeñó como Secretaria de Trabajo durante esos años, no fue, sin embargo, fruto de la casualidad, sino de una trayectoria profesional que refleja lucha, constancia, y un compromiso social que, definitivamente, la enmarca como una gran impulsora de la legislación social estadounidense del siglo $\mathrm{XX}$.

El camino no fue nada fácil, en una sociedad mayoritariamente masculina. Cuando Roosevelt la designó en los años treinta, para formar parte de su gobierno, se había estado preparando para ese momento media vida, reinventándose a sí misma, sufriendo una transformación de identidad, religión, atuendo e ideología, hasta convertirse en el personaje público conocido como Frances Perkins. Tras el cambio de identidad de Fannie Coralie Perkins se esconde, por tanto, la vida de una mujer comprometida con el mundo laboral americano, cuya influencia sigue patente hoy en día mediante mejoras tan conocidas como la Ley de Seguridad Social o la Ley para unas Normas Laborales Justas, por citar algunos ejemplos. Su vocación por proteger todos los aspectos dentro del mundo laboral del trabajador y trabajadora americanos, junto con los niños, deja un legado que sigue vigente en la historia americana actual.

\section{ETAPA DE FORMACIÓN}

Frances Coralie Perkins se crió en el seno de una familia de clase media acomodada de finales del siglo XIX (1880), educada con los principios que marcaba una sociedad victoriana y estricta, y de los que pronto se rebeló, pues fue en la Universidad de Mount Holyoke, Massachussets, donde su verdadera vocación se despertó. Gracias a una de sus profesoras de historia americana, Anna May Soule, descubrió las condiciones infrahumanas en que la mayoría de los trabajadores de la ciudad industrial de Holyoke tenían que enfrentarse diariamente. A través de esta dramática realidad, los falsos tópicos acerca de la definición de una persona pobre, como personificación de alguien sumido en la bebida o simplemente asociado a una situación inmoral, se derrumbaron. Descubrió que la pobreza también podía ser producto de un accidente laboral, por ejemplo. Por tanto, May Soule, hizo reflexionar a una joven Perkins sobre la condición del ser humano en momentos circunstanciales. Las aspiraciones de esta joven de 18 años fueron a partir de ese momento diferentes, pues descubrió que fuera de su mundo acomodado y seguro, existía una población que vivía en la miseria y que la justicia social era y debía de ser posible como un método eficaz de proteger a los más desvalidos.

En 1902, se graduó en químicas, pero tenía una idea muy clara: el trabajo social era su pasión. Y así fue durante el resto de su vida, ayudar a los más necesitados, defender a la otra mitad de americanos de injusticias sociales, descargarles del peso de una vida dura que engullía a los más débiles hacia una sociedad cada vez más capitalista y codiciosa. Comenzó a mirar hacia esa otra mitad desvalida e ignorante desde los peldaños más inferiores del trabajo social. Con tan solo veinte años, en 1904, decidió marcharse a Chicago, el centro intelectual que ofrecía mayor número de posibilidades a una mujer joven que se quería dedicar al trabajo social. Se movería entre dos mundos totalmente diferentes: clases sociales ricas y pobres, ya que aceptó un trabajo como profesora de ciencias en la universidad femenina de Ferry Hall (Illinois), la cual estaba situada en una de las zonas pudientes de Chicago, y por otro lado, no desistió en su intento de seguir involucrándose en causas sociales como voluntaria en un proyecto novedoso en una casa de acogida. Por mediación de una profesora con la que mantenía amistad, tuvo la oportunidad de ponerse en contacto con una de estas casas de acogida, la más reconocida y popular de la época: Hull House, donde comenzó a pasar los fines de semana y vacaciones como voluntaria. Se formó a nivel práctico lo que sólo había leído en libros. Las rondas que realizaba con la enfermera del distrito, mezclándose con los necesitados, los inmigrantes, los olvidados, le hizo entender que su verdadera vocación no residía en enseñar, sino en dedicarse a los más pobres. Podía haber elegido, sin embargo, instalarse en esa parte de la sociedad llena de comodidades y beneficios. Por el contrario, decidió dedicarse de lleno a ese sector de la población que más la necesitaba, como indican estas palabras: "estoy más interesada que nunca en este tipo de trabajo; y espero ser capaz de hacerlo por al menos un año muy pronto." Nunca se arrepintió de dicha elección.

Y fue en su juventud, cuando Frances se reinventó a sí misma, dejando atrás parte de su nombre, religión e ideología. El camino hacia su verdadera vocación no había hecho más que empezar. El cambio de nombre fue el primer paso en su nueva vida, pues existe evidencia de ello en el catálogo de profesores de la universidad de Ferry Hall, cuando la incluyeron como Frances Perkins y no como Fannie Coralie Perkins. No se sabe a ciencia cierta por qué decidió no volver a utilizar su segundo nombre, quizás ella misma pensó que tal nombre incitaría al chiste fácil (de hecho, cuando querían ridiculizarla o menospreciarla utilizaban este nombre), o no se la tomarían demasiado en serio si de verdad quería dedicarse al trabajo social, quizás pensó en su momento que esta nueva identidad le 
concedería ventajas a la hora de optar a un trabajo, resultaba ser un nombre neutral y serio, y además le permitía mantener sus iniciales.

Si tuvo la valentía de realizar este cambio de identidad, nada más llegar a Chicago no se quedaría atrás cuando a finales de su primer año, en 1905, decidió cambiar su religión, y abandonó la iglesia Congregacionalista por la Episcopalista (muy similar a la Católica). Este cambio de religión supuso un shock para sus padres sobre todo, ya que una familia de Nueva Inglaterra a principios de siglo, veía inconcebible ese cambio de fe. Sin embargo, supuso un paso importante para ella, ya que en momentos decisivos de su vida le serviría de guía. El mensaje cristiano de ayudar a los pobres iba muy en sintonía con la carrera profesional a la que quería dedicarse.

Si parte de su identidad la cambió, su religión anterior la rechazó, su ideología también comenzó a tambalearse como consecuencia de tener acceso directo y contacto con los más marginados. En Hull House, al que antes se ha hecho referencia, Frances presenciaba continuamente charlas entre sus visitantes sobre aspectos antes impensables para ella, estaba abierta continuamente a nuevas ideologías políticas, diametralmente opuestas con las que se había criado, como por ejemplo, el tema tan controvertido de los sindicatos, siendo considerados un ente maligno del que había que huir. Pronto, se dio cuenta en su día a día de que no era tan sencillo descargar prejuicios tan generales sobre la población más pobre que se hacinaba en corralas, sin ventilación, faltos de recursos, carentes de educación. Los desequilibrios sociales no era un tema tan fácil de resolver, los guetos existían y alguien tenía que ayudar a la erradicación de estas injusticias sociales.

En 1907, decidió dedicarse de lleno al trabajo social, y aceptó un puesto en Filadelfia, concretamente en la Philadelphia Research and Protective Association (Asociación de Protección e Investigación de Filadelfia). Era un trabajo que consistía en investigar qué ocurría con aquellas mujeres inmigrantes que llegaban a Estados Unidos. Se creía que a la mayoría se les ofrecía unos trabajos que no existían y se les obligaba a prostituirse. El trabajo de Frances, por tanto, se basaba en descubrir a los proxenetas y traficantes de drogas, acabar con esta lacra y proteger a las mujeres inmigrantes de esta explotación sexual. Un trabajo difícil y arriesgado que ocultó durante dos años a sus padres, los cuales habrían puesto el grito en el cielo, horrorizados al saber que su hija tenía que desenvolverse en tal ambiente. Su valor y constancia le dieron la fuerza para investigar 165 casas donde estas mujeres eran obligadas a trabajar, conoció los niveles más bajos del ser humano, vio de primera mano como las hacinaban en sitios insalubres y ayudó a cerrar, incluso, cuatro de estos burdeles, denunciándolo como testigo principal, testificando sobre el horror que había presenciado.

En estos años también descubrió a través de las entrevistas realizadas a mujeres que trabajaban en fábricas, que tenían salarios inferiores a los hombres (6 dólares a la semana), y se les ofrecía trabajos de peor calidad. Vivían en sótanos y su dieta se basaba en pan y plátanos. Para llegar a final de mes muchas de ellas aceptaban cenas o dinero en metálico de hombres. Evidentemente, Frances junto con otros investigadores sociales detectaron que este tipo de "regalos" y "cenas" era un pequeño paso hacia la prostitución también.

Como puede observarse hasta este momento, Perkins llevaba una vida totalmente ajena al mundo de sus progenitores, ocultando su verdadera pasión por lo social. Llegó un punto en su vida en el cual tuvo que tomar la decisión de ocuparse de lleno en su vocación, formarse en ese campo, y así lo hizo, realizó un master en 1909 en ciencias políticas (Universidad de Columbia), dejando atrás también sus años como profesora de ciencias, y consiguió un trabajo como secretaria ejecutiva para la Consumer's League de Nueva York, (Liga de Consumidores). En este nuevo puesto se concentró en cuatro áreas principalmente: conseguir regulación sanitaria para las panaderías situadas en sótanos, técnicas de prevención de incendios en fábricas, análisis de las largas jornadas y salarios de las mujeres trabajadoras, y el trabajo infantil. Llevó a cabo un estudio exhaustivo y profundo sobre estos cuatro temas, preocupantes y llenos de irregularidades en la época. Visitó cientos de panaderías, donde encontró a niños tuberculosos, gatos, ropa de trabajadores, conviviendo en el mismo sitio donde se elaboraba el pan diariamente. Unas condiciones insalubres que se atrevió a destapar, presentando un estudio con recomendaciones a la junta de sanidad.

Sus investigaciones fueron tan rigurosas y precisas que no sólo fueron utilizadas en años posteriores para la Preliminary Report of the Factory Investigating Commission (Informe Preliminar de la Comisión Investigadora de Fábricas) de 1911, sino que la eligieron como principal experta para citada comisión. Aparte de estos estudios tan valorados y útiles para el bienestar de la sociedad americana, su labor como cabildera, también de la National Consumer's League (Liga de Consumidores) consiguió enmarcarla como una joven prometedora y valiente, siendo reconocida y respetada en los altos círculos políticos. Consiguió lo que antes nadie había logrado en una década, y fue luchar por la jornada máxima de trabajo de cientos de miles de mujeres que trabajaban en las fábricas de Nueva York. A pesar de su inexperiencia y juventud, se desenvolvió magistralmente y consiguió hacer pasar la 54-Hour Bill (Ley de 54 horas), reduciendo, por tanto, a 54 horas semanales el horario máximo de estas mujeres. En el proceso de sacar adelante esta ley, conoció a una persona fundamental en su círculo de relaciones políticas, al futuro Gobernador Al Smith, uno de los hombres clave en la vida política de Perkins.

Este trabajo, en definitiva, supuso una experiencia sin igual para Perkins, un filón de nuevas aportaciones para seguir formándose en su carrera profesional y una pieza 
decisiva para poder entender mejor su éxito en puestos de gran relevancia pública posteriores.

Un punto importante a tener en cuenta en esta etapa cuasi-pública, fue que ya en estos años, se percibe una transición en el atuendo de Frances, pues con tan solo treinta años comenzó a vestir ropas demasiado serias y formales para su edad, su porte pasó a ser el de una madre de mediana edad, seria y sombría, siempre con vestido negro y collar de perlas. De hecho la prensa comenzó a llamarla, "Mother Perkins" o "Ma Perkins. Había aprendido, quizás, que en los ambientes políticos en los que ahora se movía, los hombres respetaban y valoraban más a una mujer que les recordase a su madre: "conocen y respetan a sus madres, el noventa y nueve por ciento de los hombres lo hace", una vez explicó. Por lo que hizo todo lo posible por sacar partido de su género, antes una carga para ella, y "disfrazarse" en la esfera pública de otro personaje que le hiciera sentirse más cómoda en un mundo masculino que de otro modo nunca la habría tomado en serio.

\section{ETAPA JUNTO AL GOBERNADOR AL SMITH (1919-1928)}

Uno de los hombres fundamentales en esta etapa que creyó en su valía e inteligencia fue el Gobernador de Nueva York Al Smith, con el que permaneció siete años, y uno de los primeros en arriesgarse a nombrarla presidenta de la Comisión Industrial en 1919, un puesto de gran relevancia y salario para una mujer desconocida en aquella época (recordemos que las mujeres no podían aún votar). Perkins había demostrado que estaba cualificada para dicho puesto, ya que había trabajado durante años en la Comisión Investigadora de Fábricas, siendo gran conocedora de las leyes y funcionamiento del Ministerio de Trabajo mejor que nadie.

Este trabajo supuso para Perkins conseguir logros importantes en la esfera social y otorgarle la autoridad para realizar cambios que reverterían positivamente en los trabajadores. Por primera vez en la historia del Ministerio de Trabajo de Nueva York, empezó a coordinar el trabajo de la División de inspección de fábricas y de la División de compensación a los trabajadores. Por lo tanto, mediante esta coordinación surgió la posibilidad de que los inspectores pudieran corregir condiciones peligrosas mediante las peticiones de compensación laboral de los trabajadores. También logró a través de investigaciones científicas corregir las tragedias en las fábricas. Reunió a científicos y profesionales de varios campos, relacionados con la salud en el trabajo o protección de incendios, para que investigasen situaciones graves producidas por falta de información o indiferencia y presionó para adoptar códigos al respecto.

Su compromiso era tal con todas las áreas relacionadas con el campo de lo social, que mantenía una actitud siempre activa en busca de soluciones para asegurar la vida diaria de cientos de empleados de las fábricas de Nueva York. En cierta manera se sentía responsable si se sabía de la existencia de peligros y no se actuaba rápido al respecto. Quizá siempre tuvo presente en su conciencia el terrible incendio de la Triangle Shirtwaist Company y luchaba porque nunca volviera a ocurrir una tragedia de tal calibre.

Otra área, en la que consiguió muchos progresos fue en lo relativo a enfermedades laborales. Era una época en la que se introducían nuevos químicos sin comprobar antes si tenían o no efectos tóxicos secundarios. En consecuencia era imprescindible crear una ley por la cual se responsabilizara por la salud de los empleados. Alguien tenía que concienciarse de los efectos secundarios que podían ocasionar en seres humanos. Enfermedades tales como la silicosis no estaba reconocida hasta el momento. Finalmente, consiguió hacer pasar la Ley de Indemnización por accidente laboral e incluir un gran número de enfermedades profesionales para que los trabajadores pudieran disfrutar de mayor cobertura económica, consiguiendo crear una conciencia en los empresarios cada vez que introducían un nuevo químico en la fábrica, ya que con esta ley de enfermedades ocupacionales, aprendieron que "costaba dinero envenenar a la gente".

En estos años quedaron muchos asuntos por concluir, entre ellos la gran lacra del trabajo infantil, un mal social que dañaba a una parte de la sociedad débil y desprotegida. En su etapa posteriorjunto al Gobernadory futuro presidente F.D. Roosevelt conseguiría mediante su continuo desvelo y preocupación ir perfilando y mejorando muchas leyes encaminadas a mejorar la situación de una parte de la población que directamente sufría las consecuencias de una industrialización demasiado dura y despiadada. Perkins, por tanto, había probado sobradamente su valía e inteligencia como funcionaria durante casi diez años. Cuando el Gobernador F.D. Roosevelt en 1929 la nombró Comisaria Industrial, convirtiéndose en una de las mujeres más poderosas del estado de Nueva York, sabía a ciencia cierta que no había nadie tan eficiente y capacitado para este puesto.

\section{ETAPA JUNTO AL GOBERNADOR FRANKLIN D. ROOSEVELT}

Cuando Roosevelt citó a Perkins en Hyde Park el 14 de enero de 1929 para ofrecerle el puesto de Comisaria Industrial, llevando el departamento y supervisando a cientos de empleados, incluyendo inspectores de fábricas, con un salario que pasaría de 8.500 a 12.000 dólares anuales, y convirtiéndose así en la primera mujer miembro de un gabinete en el estado de Nueva York, Perkins mantuvo una actitud imparcial y distante.

Antes de confirmar su cargo cómo Comisaria Industrial, Perkins dejó claro al nuevo Gobernador que quería una serie de cambios serios para el buen funcionamiento del Ministerio de Trabajo, también pretendía sacar adelante el programa legislativo relativo 
al trabajo infantil, prohibición del trabajo nocturno de mujeres, y de una serie de códigos que deberían ser adoptados de manera inmediata, ya que en la administración anterior no se había conseguido que progresaran. Roosevelt apoyó a Perkins desde el principio y le dio luz verde para empezar a trabajar en estos proyectos. Este nuevo período que comenzaba para Perkins fue crucial. Si Al Smith le había ayudado a formar parte de la vida pública, Roosevelt supondría un gran apoyo en su carrera profesional posterior hasta llegar a convertirse en Secretaria de Trabajo. Los diez años anteriores de su carrera habían demostrado dar su fruto, su lucha por conseguir justicia social parecía en principio tener un apoyo muy fuerte del nuevo Gobernador. Los dos estaban de acuerdo en mantener un programa por y para la gente del estado de Nueva York. Aunque el período que tuvieron que afrontar no fuera el más halagüeño, Perkins tomó su nuevo cargo con una actitud propia en ella, de responsabilidad y compromiso por mejorar la vida laboral de los ciudadanos del estado de Nueva York.

Tanto Roosevelt como ella se enfrentaron a una crisis económica grave en el año 1929, teniendo que adoptar medidas drásticas y eficientes para subsanar una economía destruida por causas especulativas. Las recomendaciones prácticas para acabar o al menos aliviar tal situación son importantes destacar, la creación de la comisión de "Stabilization of Employment" (Estabilización de Empleo) para analizar las causas de la crisis y conseguir estabilizar tanto los empleos como la producción fue una idea novedosa en el momento. Nunca antes se planteó, por ejemplo, una semana laboral de tan sólo cinco días, como método eficaz de extender el trabajo ante una situación realmente crítica, y poder aliviar la tasa de desempleo.

Durante esta etapa bajo la administración de Roosevelt, Perkins siguió abogando por perfeccionar algunas leyes que no habían sido resueltas en el mandado de $\mathrm{Al}$ Smith, ya que sólo consiguió incluir por ley un listado de enfermedades profesionales concretas. Lo que pretendía ahora Perkins era suprimir esta lista y añadir una cláusula que incluyera cualquier enfermedad que pudiera incapacitar a un empleado como consecuencia a una exposición directa en el trabajo. Consiguió, finalmente, en esta etapa, hacer pasar una ley con muchas enmiendas que cubrían casi cualquier enfermedad a excepción de la silicosis.

En resumen, esta fase junto a Franklin Roosevelt creó un equipo de trabajo positivo y pretendió tomar parte activa en años de crisis. La capacidad de Perkins de saber mostrar al futuro presidente los vacíos en legislación, los errores, las negligencias, hicieron de ella una figura esencial en reforma laboral. Posteriormente en 1933, Roosevelt volvería a confiar en su inteligencia y lealtad nombrándola Secretaria de Trabajo de su Gabinete político como presidente de los Estados Unidos. Trabajó durante 16 años activamente por impulsar la legislación estadounidense. Consiguió una reestructuración de la sociedad americana nunca antes conocida, ya que luchó enérgicamente por incluir la jornada laboral de ocho horas, seguro de desempleo, compensación laboral, salario mínimo, y abolición de la gran miseria humana del trabajo infantil.

Si en los años anteriores demostró su compromiso y tenacidad por luchar contra las injusticias sociales, como Secretaria de Trabajo, logró cumplir todos los objetivos que se había planteado durante media vida. Si Fannie Coralie Perkins se había reinventado a sí misma para luchar por el bienestar social americano, Frances Perkins demostró que todos los cambios físicos que ella misma optó aceptar merecieron la pena, su legado lleno de beneficios así lo documenta: seguro de desempleo, compensación económica laboral, jornada de ocho horas y salario mínimo, Seguridad Social, prevención de accidentes laborales y de incendio en el trabajo, y la abolición del trabajo infantil. Sus palabras años atrás reflejan un compromiso y un nivel de involucración que así lo corrobora: “Vine a trabajar para Dios, F.D.R y los millones de trabajadores sencillos, corrientes y olvidados."

\section{CONCLUSIÓN}

Frances Perkins fue una figura clave para la vida de los trabajadores americanos, un modelo de compromiso y pasión hacia su verdadera vocación: el trabajo social. A través de su educación universitaria, en Mount Holyoke, se iluminaron caminos que cambiaron la trayectoria de su vida profesional, llegando a cambiar nombre, atuendo, religión y parte de la ideología con la que se había educado. Cuando Frances Perkins descubrió su verdadera pasión por ayudar al trabajador americano, comenzó su plan personal para conseguir dicho objetivo. Pasó por diferentes puestos, en los cuales demostró valentía, talento y tenacidad, como profesional y como ser humano. Su paso por la Liga de Consumidores de Nueva York, actuó de verdadero trampolín para demostrar que realmente no era un capricho de una niña de clase media de Worcester. Investigó cientos de fábricas, demostró a la sociedad americana las condiciones insalubres en las que se elaboraba el pan que se comían diariamente, y sacó a la luz peligros que existían para que no volviera a ocurrir un incendio tan horrible como el de la Triangle Shirtwaist Company.

Cuando en 1933 fue nombrada Secretaria de Trabajo, no fue por casualidad ni arbitrariamente, había estado preparándose para este puesto pacientemente, siendo merecedora del mismo. Los cambios personales que sufrió por elección propia merecieron la pena. Fannie Coralie Perkins triunfó tras la máscara pública y victoriosa de Frances Perkins.

\section{REFERENCIAS BIBLIOGRÁFICAS}

Addams, J., Twenty Years at Hull House, Boston, St. Martin's, 1999. 
Colman, P., A Woman Unafraid. The Achievements of Frances Perkins, Nueva York, Maxwell Macmillan International, 1993.

Downey, K., The Woman Behind the New Deal, Nueva York, Random House, 2009.

Josephson, M., Al Smith: Hero of the Cities, A Political Drawing of the Papers of Frances Perkins, Boston, Houghton Mifflin, 1969.

Lawson, D., Frances Perkins: First Lady of The Cabinet, New York, Abelard-Schuman, 1966.

Martin, G., Madam Secretary Frances Perkins, Boston, Houghton Mifflin, 1976.

Mohr, L. H., Frances Perkins: "That Woman in FDR's Cabinet!", Croton-on-Hudson, New York, North River Press, 1979.

Pasachoff, N., Frances Perkins Champion of the New Deal, Oxford. New York, O.U.P, 1999.

Perkins, F., People At Work, New York, John Day Co., 1934.

----, The Roosevelt I Knew, London, Hammond, Hammond, 1946. 